\title{
Work-related health problems in salt workers of Rajasthan, India
}

\begin{abstract}
Background: About 20,000 men and women are engaged in the production of salt in Rajasthan alone, which is an important unorganized sector. The salt workers are exposed to adversities of environmental conditions as well as salt in the environment. There is a lack of information about their occupational health problems. Aims: The study aimed to identify work-related health problems experienced by the salt workers. Settings and Design: Data were collected in the health camps held near salt sites. Materials and Methods: Workers of salt manufacturing units were invited for their free health examination. Statistical Analysis: Analysis of the data was carried out using Epi-Info 2002 software. Results: Prevalence of ophthalmic symptoms was $60.7 \%$, that of dermatological symptoms was $43.8 \%$ and symptoms like headache, giddiness, breathlessness, muscular and joint pains were experienced by $52.1 \%$ salt workers. The ophthalmic problems were most common, probably due to irritation by direct sunlight and its glare caused by salt crystals and brine as well as irritation caused by fine salt particles suspended in the air of the working environment. Traumatic ulcers, dermatitis, muscular and joint pains, headache and giddiness were other more common symptoms observed among the workers. Prevalence of hypertension was $12.0 \%$. Conclusions: Looking at the large number of salt workers exposed to salt and facing occupational health problems, there is a need for developing a mechanism for prevention of these problems in them.
\end{abstract}

Key words: Occupational health problems, prevalence, salt-workers, symptoms

\section{INTRODUCTION}

About 20,000 workers are engaged in the production of salt in Rajasthan, which is an important unorganized sector ${ }^{[1]}$ in western India. Inland water or lake water rich in salt content is kept in wide and open pans manually constructed on the surface of earth from where water evaporates under direct sunlight and salt crystallizes at the bottoms of brine pans. Salt workers engage in various processes of salt manufacturing - viz., sweeping the salt crystals with a wooden spade; heaping of salt crystals at the edges of pans; loading, weighing, milling, packing or transportation of salt. The workers are exposed to adversities of environmental conditions as well as salt in the environment. A cross-sectional study was carried out to identify the workrelated health problems experienced by salt workers.

\section{MATERIALS AND METHODS}

The occupational health camps were organized at Sambhar, Nawa and Phalodi in collaboration with owners of salt-manufacturing units and the Department of Salt, Government of India. The sites were selected on the basis of total production of salt at different sites. Workers of nearby salt manufacturing units were invited for their free health examination. The workers who were absent on the days of the health camp were excluded from the study. Each camp lasted for about 5 days. The workers who visited the camp were registered and interviewed after obtaining their informed consent. Information on age (in completed years), gender, detailed occupational history including exact nature of job and duration of working in salt industry was recorded in the predesigned schedules. After initial rest for $5 \mathrm{~min}$, three readings of blood pressure were taken using electronic blood pressure instrument (Omron T4 model) in supine position on right arm at an interval of 3-5 min. JNC-VI criteria were used for making the diagnosis of hypertension. ${ }^{[2]}$ Analysis of the data was carried out using EpiInfo 2002 software. This project was approved by the Scientific Advisory Committee of the National Institute of
Raman Sachdev, Murli L. Mathur, K. R. Haldiya, H. N. Saiyed* Desert Medicine Research Centre, (ICMR),

Jodhpur - 342005,

*National Institute of Occupational Health, (ICMR), Ahmedabad 380016, India

For correspondence: Raman Sachdev, Desert Medicine Research Centre, New Pali Road, Jodhpur 342 005, India. E-mail: sachraman@hotmail.com

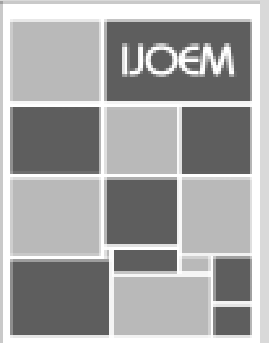


Occupational Health, Ahmedabad, India. The procedures followed were in accordance with the Helsinki Declaration.

\section{RESULTS}

In all, 865 salt workers were studied $84.5 \%$ of them were males. All the workers were above the age of 14 years. Their general characteristics are described in Table 1. Prevalence of work-related symptoms was $85.9 \%$ among salt workers. Prevalence of ophthalmic symptoms was $60.7 \%$, that of dermatological symptoms was $43.8 \%$ and symptoms like headache, giddiness, breathlessness, muscular and joint pains were present in $52.1 \%$ of salt workers [Table 2]. The common ophthalmic symptoms were glare (45.7\%), redness of eyes (41.6\%) and burning sensation in eyes (38.7\%). Smaller number of workers also complained of excessive watering in eyes (10.6\%), dimness of vision (9.9\%), photophobia (2.1\%) and pain in eyes (1.5\%). Among dermatological symptoms, itching (8.9\%), ulceration (9.5\%), thickness of skin (8.1\%), cracks in skin (6.5\%) and burning sensation in skin (4.8\%) were complained of by the salt workers. Thickness of skin was complained of mainly over palms of male workers. Symptoms pertaining to other systems like giddiness, headache, pain in joints, pain in muscles and general weakness were more prevalent in females (73.9\%) than in males $(48.0 \%)(P<0.005)$. Giddiness was particularly complained of while standing up from sitting posture during working hours. Headache, joint pain and muscular pain were other work-related symptoms and the severity of these symptoms reduced after taking some rest. Breathlessness was complained of by $6.2 \%$ of workers.

The prevalence of hypertension among the workers increased with age in both the sexes. It was $6.1 \%$ in male workers below

Table 1: General characteristics of the study subjects

\begin{tabular}{lc}
\hline Characteristics & Salt workers (n=865) \\
\hline Age (years) & $32.17 \pm 10.78$ \\
Gender M/F (\%) & $84.5 / 15.5$ \\
Literacy (\%) & 43.6 \\
Income (Rs. per annum) & $20077 \pm 14882$ \\
Smokers (\%) & 32.6 \\
Alcohol users (\%) & 9.5 \\
BMl Kg/m ${ }^{2}$ & $19.08 \pm 2.82$ \\
Duration of salt work (years) & $10.12 \pm 7.37$ \\
Vegetarians (\%) & 66.4 \\
\hline
\end{tabular}

25 years age, though hypertension was not observed in females of the same age. Overall prevalence of hypertension was $12.0 \%$. It was not significantly different in males and females.

\section{DISCUSSION}

Working in salt industry exposes the working population to direct contact with inhalable salt dust, salt crystals as well as concentrated brine, physical stress of hard manual labor, direct bright sunlight and glare due to sunlight reflected by salt crystals and brine surface. Most common symptoms observed among salt workers were those pertaining to eyes. These might be due to irritation caused by exposure to salt dust and reflection of bright sunlight by salt crystals and brine. Itching, cracks and burning sensation in skin might be caused by direct contact with salt and the impurities found in salt, like sulfates, magnesium, calcium, potassium, etc. Ulcers on skin were mostly traumatic in origin. These were present on feet, legs and hands. When workers collect the salt crystals using spades, the crystals hit the feet and legs, while hands sustain injury from the spade. Thickening of skin over palms and feet may be due to hyperkeratosis caused by friction with spades and salt crystals. The physical stress of hard work in sunlight might be a potent cause of headache, giddiness, muscular pain, joint pain and general weakness present among the workers. These symptoms were more common in females, probably due to higher prevalence of anemia in them. Notable prevalence of visual defects (7.7\%), hypertension (4.7\%) and musculoskeletal problems has also been reported among fishermen, who are also exposed to salty sea water and sunlight. ${ }^{[3]}$

Present study did not reveal high prevalence of hypertension in salt workers. In a study in villages of Rajasthan, $12 \%$ males had borderline isolated systolic hypertension, $2 \%$ had definite isolated systolic hypertension and the overall prevalence of hypertension and its subtypes was $24 \%$ in males and $17 \%$ in females. ${ }^{[4,5]}$ Skrobonja and Kontosic ${ }^{[6]}$ also reported hypertension in $10.6 \%$ of harbor workers of Croatia, who were also exposed to salt rich water and hard manual labor. In a study of hypertension in workers exposed to salt, O'Sullivan and Parker ${ }^{[7]}$ reported that prevalence of hypertension in salt workers was not found to be different from a similar group of

Table 2: Percent prevalence of various symptoms among salt workers

\begin{tabular}{|c|c|c|c|c|c|}
\hline Ophthalmic symptoms & $\%$ Prev. & Dermatological symptoms & $\%$ Prev. & Other symptoms & $\%$ Prev. \\
\hline All ophthalmic symptoms & 60.7 & All dermatological symptoms & 43.8 & All other symptoms & 52.1 \\
\hline Glare & 45.7 & Itching & 8.9 & Giddiness & 28.2 \\
\hline Redness of eyes & 41.6 & Ulceration & 9.5 & Headache & 26.8 \\
\hline Burning of eyes & 38.7 & Thickening of skin & 8.1 & Joint pains & 23.7 \\
\hline Excessive watering & 10.6 & Cracks & 6.5 & Muscular pain & 22.4 \\
\hline Dimness of vision & 9.9 & Burning sensation & 4.8 & Breathlessness & 6.2 \\
\hline Photophobia & 2.1 & Dryness & 3.5 & General weakness & 3.9 \\
\hline Pain in eyes & 1.5 & & & & \\
\hline Night blindness & 0.7 & & & & \\
\hline
\end{tabular}


workers not occupationally exposed to salt. Present study highlights the need for developing provision for prevention of occupational health problems in workers engaged in salt production.

\section{ACKNOWLEDGEIMENTS}

Ministry of Health and Family Welfare, Government of India had financed the project entitled "Prevention and Control of Occupational Health Hazards among the Salt workers working in Desert areas of Gujarat and Western Rajasthan". Authors are grateful to the Ministry as all the data presented in this paper were collected under this project. Authors are also grateful to the staff of Salt Department, Government of India and the staff of Hindustan Salts Ltd., Jaipur, India who helped in this study."

\section{REFERENCES}

1. Haldiya KR, Mathur ML, Sachdeva R, Beniwal VK, Singh MB, Yadav
SP, et al. Morbidity pattern of desert population engaged in salt manufacture in Rajasthan. J Indian Med Assoc 1995;93:95-7.

2. The sixth report of the Joint National Committee on prevention, detection, evaluation and treatment of high blood pressure. Arch Intern Med 1997;157:2413-46.

3. Filikowski J, Rzepiak M, Renke W. Health problems of deep sea fishermen. Bull Inst Marit Trop Med Gdynia 1998;49:45-51.

4. Gupta R. Trends in hypertension epidemiology in India. J Hum Hypertens 2004;18:73-8.

5. Gupta R, Sharma AK. Prevalence of hypertension and subtypes in an Indian rural population: Clinical and electrocardiographic correlates. J Hum Hypertens 1994;8:823-39.

6. Skrobonja A, Kontosic I. Arterial hypertension in correlation with age and body mass index in some occupational groups in the harbour of Rijeka, Croatia. Ind Health 1998;36:312-7.

7. O'Sullivan JJ, Parker GD. Investigation of the blood pressure levels of workers occupationally exposed to salt. Occup Med (Lond) 1992;42:15-8.

Source of Support: Ministry of Health and Family Welfare, Government of India, Conflict of Interest: None declared.

\section{Author Help: Reference checking facility}

The manuscript system (www.journalonweb.com) allows the authors to check and verify the accuracy and style of references. The tool checks the references with PubMed as per a predefined style. Authors are encouraged to use this facility before submitting articles to the journal.

- The style as well as bibliographic elements should be $100 \%$ accurate to get the references verified from the system. A single spelling error or addition of issue number / month of publication will lead to error to verifying the reference.

- $\quad$ Example of a correct style

Sheahan P, O'leary G, Lee G, Fitzgibbon J. Cystic cervical metastases: Incidence and diagnosis using fine needle aspiration biopsy. Otolaryngol Head Neck Surg 2002;127:294-8.

- Only the references from journals indexed in PubMed would be checked.

- $\quad$ Enter each reference in new line, without a serial number.

- $\quad$ Add up to a maximum 15 reference at time.

- If the reference is correct for its bibliographic elements and punctuations, it will be shown as CORRECT and a link to the correct article in PubMed will be given.

- If any of the bibliographic elements are missing, incorrect or extra (such as issue number), it will be shown as INCORRECT and link to possible articles in PubMed will be given. 